\title{
Radiocarbon content of carbon dioxide and methane in hydrothermal fluids of Okinawa Trough vents
}

\author{
Shinsuke Kawagucci, ${ }^{1,2,3 *}$ Yohei Matsui ${ }^{3,4}$ and Gretchen L. FrüH-Green ${ }^{1}$ \\ ${ }^{1}$ Institute of Geochemistry \& Petrology, ETH Zürich, Zürich, Switzerland \\ ${ }^{2}$ Super-cutting-edge Grand and Advanced Research (SUGAR) Program, Institute for Extra-cutting-edge Science and Technology \\ Avant-garde Research (X-star), Japan Agency for Marine-Earth Science and Technology (JAMSTEC), Yokosuka, Japan \\ ${ }^{3}$ Research and Development Center for Submarine Resources, JAMSTEC, Yokosuka, Japan \\ ${ }^{4}$ Atmosphere and Ocean Research Institute (AORI), The University of Tokyo, Kashiwa, Japan
}

(Received September 14, 2019; Accepted April 14, 2020)

\begin{abstract}
Here we quantify radiocarbon $\left({ }^{14} \mathrm{C}\right)$ content in $\mathrm{CO}_{2}$ and $\mathrm{CH}_{4}$ from hydrothermal fluids collected at 5 vent sites in the Okinawa Trough. These data provide preliminary insights on how different carbon sources and circulation processes contribute to vent fluids and take into consideration all potential contaminations during sample processing and analysis with accelerator mass spectrometer. For $\mathrm{CO}_{2},{ }^{14} \mathrm{C}$-dead values observed in fluids of most sites (Hatoma, Hitoshi, Noho) demonstrate the complete removal of the inorganic carbon in the recharged seawater. Conversely, the significantly positive ${ }^{14} \mathrm{CO}_{2}$ are detected in fluids from the Daiyon-Yonaguni site, which implies the persistence of the recharged seawaterderived inorganic carbon and/or a contribution from thermal degradation of sedimentary ${ }^{14} \mathrm{C}$-containing carbon during fluid upwelling. The $\mathrm{CH}_{4}$ in these fluids were predominantly ${ }^{14} \mathrm{C}$-dead or nearly ${ }^{14} \mathrm{C}$-dead, suggesting a source of deepburied, ${ }^{14} \mathrm{C}$-dead sedimentary carbon. The methods outlined in our study exemplify a useful way of elucidating radiocarbon contents of geofluids, and provide future studies with a means to improve our understanding of carbon circulation between hydrosphere and lithosphere.
\end{abstract}

Keywords: hydrothermal vent, C-14, subseafloor, carbon cycle

\section{INTRODUCTION}

Radiocarbon $\left({ }^{14} \mathrm{C}\right)$ is a cosmogenic radio-active nuclide with a half-life of 5730 years. Because no ${ }^{14} \mathrm{C}$ is detectable in a carbon reservoir that is isolated from atmospheric carbon after $\sim 50,000$ years, ${ }^{14} \mathrm{C}$ content serves as a critical indicator of evaluating relative contribution of various carbon reservoirs, especially at boundaries between the ${ }^{14} \mathrm{C}$-rich hydrosphere and ${ }^{14} \mathrm{C}$-poor lithosphere. Progressive improvement of accelerator mass spectrometry (AMS) and AMS-compatible sample processing enable us to quantify ${ }^{14} \mathrm{C}$ content with smaller sample size and shorter analytical time compared to traditional decay counting (Roberts et al., 2007; Ruff et al., 2010; Lang et al., 2013; Synal, 2013; Pack et al., 2015; Wacker et al., 2016; Haghipour et al., 2019). As such, AMS-based ${ }^{14} \mathrm{C}$ measurement and ${ }^{14} \mathrm{C}$ tracer have been established in recent years as a vital tool for understanding biogeochemical carbon cycles (Trumbore, 2009; Ishikawa et al., 2013; Blattmann et al., 2019).

*Corresponding author (e-mail: kawagucci@jamstec.go.jp)

Copyright $(92020$ by The Geochemical Society of Japan.
Deep-sea hydrothermal activity drives elemental fluxes between seawater in oceans and the lithosphere (Elderfield and Schultz, 1996). At sites exhibiting hightemperature venting, concentrations of $\mathrm{CO}_{2}$ and $\mathrm{CH}_{4}$ in the hydrothermal fluid are commonly higher than those of the ambient seawater (e.g., Kawagucci, 2014), demonstrating a net input of $\mathrm{CO}_{2}$ and $\mathrm{CH}_{4}$ to the oceanic hydrosphere through hydrothermal activity. The precise origins of this abundant $\mathrm{CO}_{2}$ and $\mathrm{CH}_{4}$ in the hydrothermal fluid, however, remain unclear; the same applies to the fate of dissolved inorganic carbon in the seawater (SW-DIC), which penetrates into the lithosphere as the first step of subseafloor hydrothermal fluid circulation (e.g., Proskurowski et al., 2004).

The ${ }^{14} \mathrm{C}$ content of $\mathrm{CO}_{2}$ and/or $\mathrm{CH}_{4}$ in these high-temperature hydrothermal fluids offer key constraints to answer these questions. Radiocarbon data have thus far only been reported from Endeavour vents in the northeastern Pacific (Proskurowski et al., 2004) and the Guaymas Basin (Pearson et al., 2005). Although radiocarbon contents have also been reported from moderate-temperature venting system at the Lost City site off-axis of the MidAtlantic Ridge (Proskurowski et al., 2008) and the Von Damm site in the Mid-Cayman Spreading Centre 


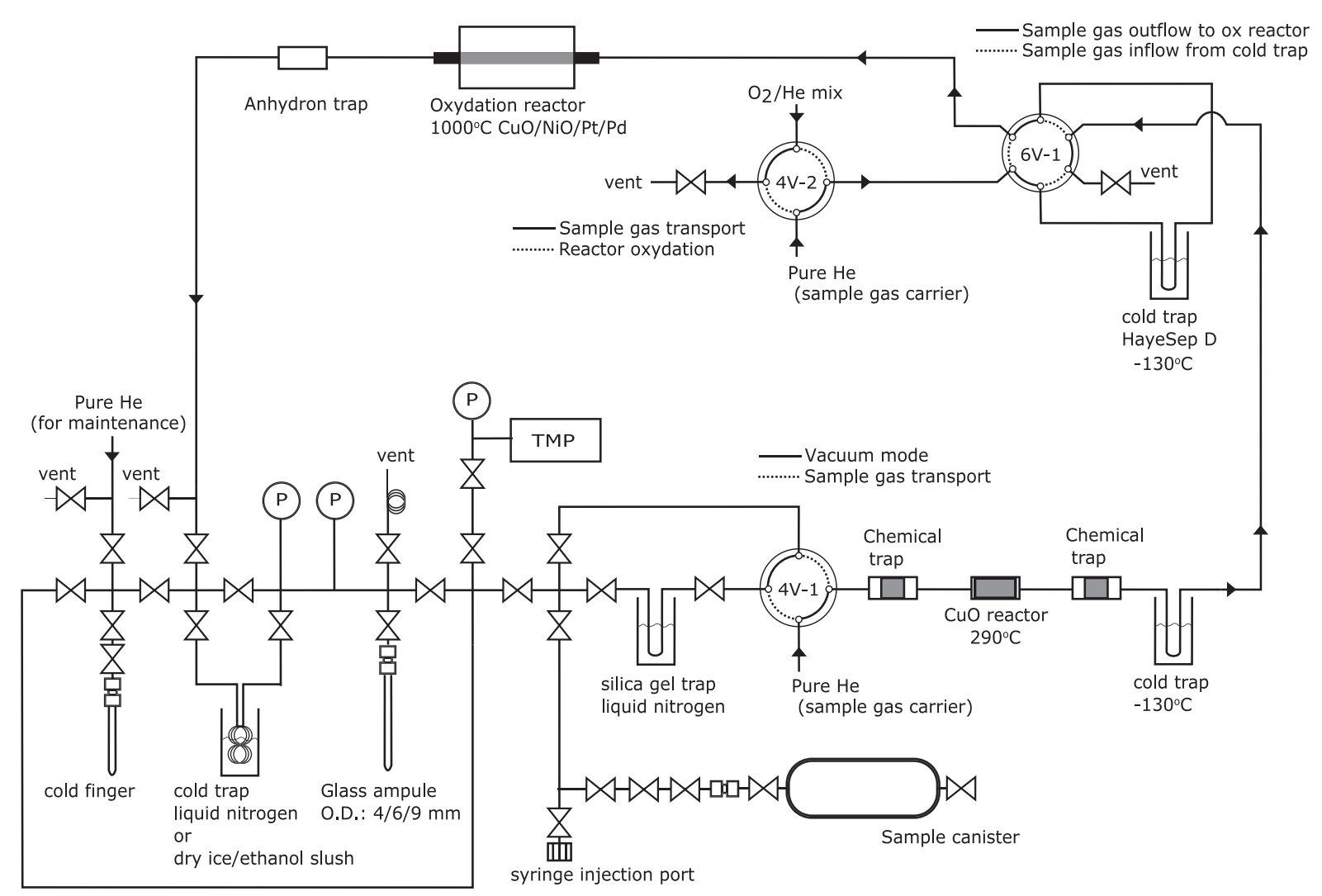

Fig. 1. Purification and oxidation line. Abbreviation " $P$ " and "TMP" respectively represent pressure gauge and turbomolecular pump.

(McDermott et al., 2015), these 2 sites are unusual in having fluid $\mathrm{CO}_{2}$ concentrations lower than or comparable to SW-DIC. Furthermore, little information was given on the possibility of ${ }^{14} \mathrm{C}$ contamination during sample processing in these studies, although this should be crucial due to atmospheric $\mathrm{CO}_{2}$ and $\mathrm{CH}_{4}$ being highly enriched in ${ }^{14} \mathrm{C}$ (Hua et al., 2013; Wahlen et al., 1989).

In the present study, we determined ${ }^{14} \mathrm{C}$ contents of $\mathrm{CO}_{2}$ and $\mathrm{CH}_{4}$ in high-temperature hydrothermal fluids collected at 5 vent sites in the Okinawa Trough in order to understand their source and behavior through the subseafloor hydrothermal processes. Furthermore, we carefully examined all potential and possible ${ }^{14} \mathrm{C}$ contaminations during sample processing all the way from hydrothermal fluid sampling to the AMS measurement, prior to discussing likely mechanisms controlling ${ }^{14} \mathrm{C}$ contents in Okinawa Trough vent fluids.

\section{SAMPLING AND METHOdS}

\section{Sampling}

High-temperature hydrothermal fluids were collected between 2014-2017 during expeditions of KY14-02, NT15-02, and KR16-16 at five deep-sea vent sites in the
Okinawa Trough: Daiyon-Yonaguni (DY) (Konno et al., 2006; Suzuki et al., 2008), Hatoma (Toki et al., 2016), Hitoshi (Nakamura et al., 2015; Miyazki et al., 2017a), Noho (Nakamura et al., 2015; Miyazki et al., 2017a), and Yokosuka (Miyazaki et al., 2017b) (Fig. 1). The DY site is located in the low-point of a valley where high sedimentation rate is expected due to topographic effect by the surrounding high walls (Ishibashi et al., 2014a; Wu et al., 2019), while the main vents of the other four sites are located either at the top or on the slope of submarine knolls where less particles are to accumulate.

Radiocarbon content of the SW-DIC 1000 m below the sea surface in the Okinawa Trough was reported as $\sim 85$ pMC (defined by Eq. (2), see below) (Honda et al., 2000). Radiocarbon dating by planktonic foraminifera buried in seafloor sediments yielded $\sim 20 \mathrm{ky}(\sim 9 \mathrm{pMC})$ at 19 and $4 \mathrm{~m}$ below the seafloor near the DY site and the close-by sites Hitoshi and Noho, respectively (Kao et al., 2005; Ijiri et al., 2005; Shao et al., 2016).

Seafloor fluid sampling was conducted with pressuretight fluid samplers WHATS-2 (Saegusa et al., 2006) or WHATS-3 (Miyazaki et al., 2017a); on-board subsampling and processing followed procedures presented in previous publications using these samplers. 
Flow-through mechanism implemented in the WHATSseries samplers allows sufficient substitution of pre-filled fluids by the target geofluid and prevents air-derived compounds from being retained in the sample bottles after fluid sampling (see (Miyazaki et al., 2017a) for more details).

\section{Sample processing onboard}

Fluids contained in the pressure-tight sample bottles were subsampled immediately after the recovery on-board research vessels from the seafloor. Each sample bottle was connected to a vacuum line typically consisting of a gas extraction portion made from glass, subsampling bottles, pressure gauges, and an oil-rotary vacuum pump. The vacuum line exhibited inner pressure as low as $10^{-2} \mathrm{kPa}$ and rate of pressure increase as low as $1 \times 10^{-2} \mathrm{kPa}$ every 10 minutes, before each fluid introduction. The entire body of fluid in a bottle was introduced into the extraction portion and mixed with solid reagents, sulfamic acid $\left(\mathrm{H}_{3} \mathrm{NSO}_{3}\right)$ and cadmium acetate $\left(\mathrm{Cd}\left(\mathrm{CH}_{3} \mathrm{COO}\right)_{2}\right)$, to extract inorganic carbon as $\mathrm{CO}_{2}$ and precipitate $\mathrm{H}_{2} \mathrm{~S}$ as sulphide minerals. The gases extracted were diffused into a 2-L glass container as subsamples for ${ }^{14} \mathrm{C}$ analyses and 50-mL stainless-steel bottles for compositional and stable isotope analyses. Pressure at the time of sample gas diffusion to the sample canisters was no lower than 17 $\mathrm{kPa}$, while water vapor pressure of $\sim 3 \mathrm{kPa}$ at laboratory temperature was included. Pressures after the gas extraction process $(\sim 15$ minutes $)$ fluctuated only by factors within the $10^{-2} \mathrm{kPa}$ order, and air contamination was no greater than $0.1 \mathrm{kPa}$. Every whole-gas sub-sample contained $>50 \%$ of $\mathrm{CO}_{2}$ and exhibited $\mathrm{CH}_{4} / \mathrm{CO}_{2}$ ratios of $>1 \%$, quantified by gas chromatograph analyses with $\sim 10 \%$ analytical uncertainty. Stable isotope ratios of $\mathrm{CO}_{2}$ and $\mathrm{CH}_{4}$ were also quantified by isotope-ratio mass spectrometers (IRMS) with analytical uncertainty within 0.5 permil (Table 1 ). The liquid phase, remaining in the extraction portion, was also subsampled for onshore $\mathrm{Mg}$ concentration analyses with $\sim 2 \%$ analytical uncertainty. Results from sample analyses without ${ }^{14} \mathrm{C}$ have already been partially reported (Miyazaki et al., 2017a, b).

\section{Purification and oxidation}

Purification of $\mathrm{CO}_{2}$ and $\mathrm{CH}_{4}$ from the whole-gas subsample was conducted in shore-based laboratory at Japan Agency for Marine-Earth Science and Technology (JAMSTEC). The standard "swab test" confirmed negligible pollution in the purification room, although the building has a radio-active isotope laboratory (Kawagucci et al., 2018b). A stainless-steel purification line, constructed based on Pack et al. (2015) and Okumura et al. (2016) with some minor modifications, functions as a conjunction between the vacuum line and a helium-flow gas chromatograph line (Fig. 1). The vacuum line was

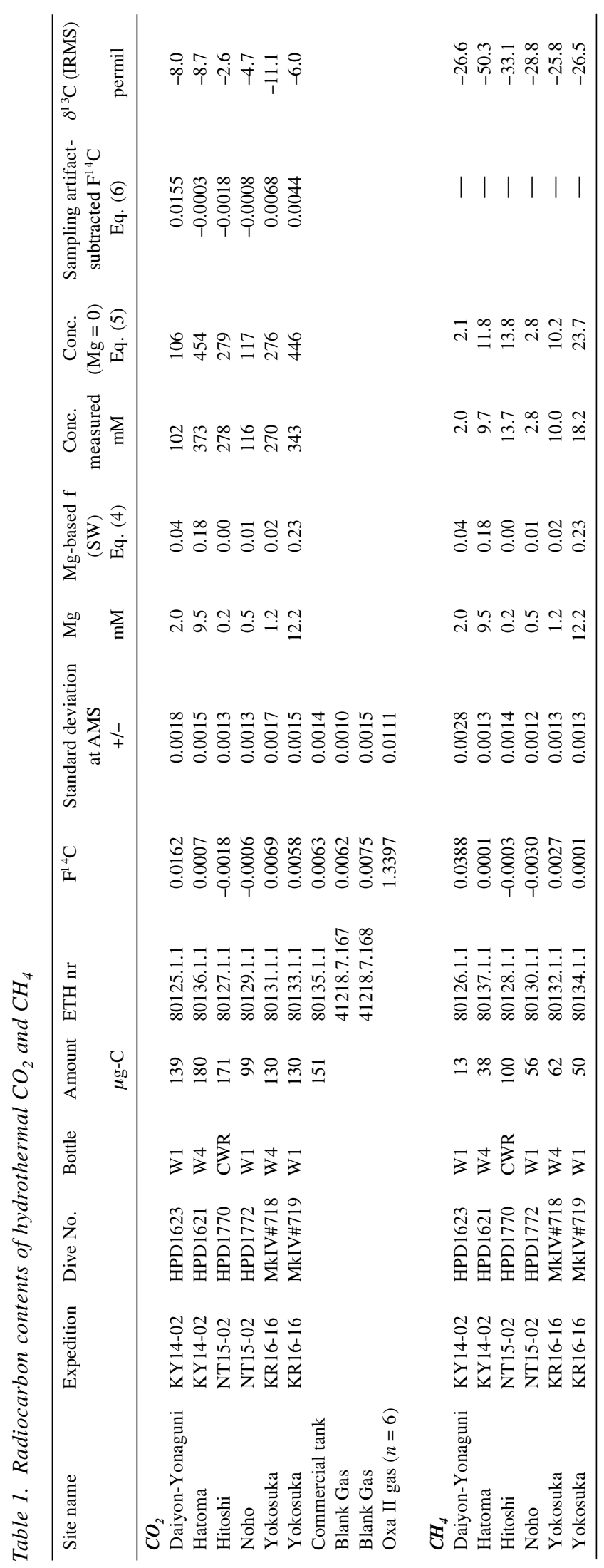


evacuated by a turbomolecular pump and baked for one day before operation for background pressure lower than $10^{-3} \mathrm{kPa}$. Ultra-pure grade $\mathrm{He}(>99.9999 \%)$ was further purified by Molecular Sieve 5A trap at $\mathrm{LN}_{2}$ temperature $\left(-196^{\circ} \mathrm{C}\right)$ for the helium-flow line.

For $\mathrm{CO}_{2}$ purification, the conventional purification method was applied using the vacuum line. First, an aliquot of the whole-gas subsample, which contained $\sim 1$ mg-C $\mathrm{CO}_{2}$, was introduced. After water removal at a trap held at $-72^{\circ} \mathrm{C}$ (dry ice/ethanol slush), $\mathrm{CO}_{2}$ was condensed on a $9 \mathrm{~mm}-\mathrm{OD}$ glass finger held at $-196^{\circ} \mathrm{C}\left(\mathrm{LN}_{2}\right)$ followed by evacuation of the non-condensable gas. The $\mathrm{CO}_{2}$ was evaporated once to quantify the amount barometrically, following which, an appropriate volume $(\sim 100 \mu \mathrm{g}-\mathrm{C}$, Table 1$)$ was condensed into a 4 or $6 \mathrm{~mm}-$ OD glass ampule, and finally this ampule was sealed with a blowtorch. Blank $\mathrm{CO}_{2}$ levels, quantified by the same procedure above but without sample introduction, was negligible $(<0.1 \mu \mathrm{g}-\mathrm{C})$.

For $\mathrm{CH}_{4}$, first an aliquot of the whole-gas subsample was introduced into the vacuum line and concentrated onto a silica gel trap (silica gel packed into a tube $10 \mathrm{~cm}$ in length and $\left.1 / 4^{\prime \prime}-\mathrm{OD}\right)$, at $-196^{\circ} \mathrm{C}\left(\mathrm{LN}_{2}\right)$. A helium stream set at $50 \mathrm{~mL} / \mathrm{min}$ was introduced to pass through the silica gel trap, which was then heated to $98^{\circ} \mathrm{C}$ (boiled water) to evaporate and blow the concentrated gases including $\mathrm{CH}_{4}$. Sample gases on the stream were sequentially passed through: 1) a chemical trap, filled with magnesium perchlorate $\left(\mathrm{Mg}\left(\mathrm{ClO}_{4}\right)_{2}\right)$ and Ascarite II (sodium hydroxide-coated silica gel) to remove water and $\mathrm{CO}_{2} ; 2$ ) a glass tube having $\mathrm{CuO}$ wires held at $290^{\circ} \mathrm{C}$ for the oxidation of $\mathrm{CO}$ to $\mathrm{CO}_{2}$; 3) another chemical trap; 4) a coiled tube held at $-130^{\circ} \mathrm{C}$ (n-pentane/LN $\mathrm{L}_{2}$ slush) for precipitation of volatile organic compounds without $\mathrm{CH}_{4}$; and 5) a stainless-steel tube filled with HayeSepD (60/80 mesh, 3 cm-long, $1 / 8^{\prime \prime}$-OD tube) held at $-130^{\circ} \mathrm{C}$ ( $n$-pentane/ $\mathrm{LN}_{2}$ slush) to capture the $\mathrm{CH}_{4}$ while allowing $\mathrm{H}_{2} / \mathrm{N}_{2} / \mathrm{O}_{2} / \mathrm{Ar}$ to pass through (Okumura et al., 2016). After turning the 2position valve to introduce another helium stream set at $3 \mathrm{~mL} / \mathrm{min}$ for the HayeSepD trap, concentrated gases were evaporated by heating (boiled water) and transported to the main oxidation reactor consisting of a glass tube filled with $\mathrm{CuO} / \mathrm{NiO}$ chips and $\mathrm{Pt} / \mathrm{Pd}$ wires for $\mathrm{CH}_{4}$ oxidation to $\mathrm{CO}_{2}$, held at $1000^{\circ} \mathrm{C}$. Ethane and other light molecular weight organic compound may also be oxidized to $\mathrm{CO}_{2}$ whereas their mixing ratios are two or three orders of magnitude lower than $\mathrm{CH}_{4}$ (e.g., Miyazaki et al., 2017a). The $\mathrm{H}_{2} \mathrm{O}$ produced was removed by a tube filled with $\mathrm{Mg}\left(\mathrm{ClO}_{4}\right)_{2}$ while the $\mathrm{CO}_{2}$ produced was condensed at a $\mathrm{U}$-shaped stainless-steel tube held at $-196^{\circ} \mathrm{C}\left(\mathrm{LN}_{2}\right)$. Headspace gas of the U-shaped trap was evacuated, followed by the transfer of $\mathrm{CO}_{2}$ into a 4 or $6 \mathrm{~mm}-\mathrm{OD}$ glass tube, and lastly this ampule was sealed with a blowtorch. Recovery rate of $\mathrm{CH}_{4}$ as $\mathrm{CO}_{2}$ was not lower than $80 \%$.
Blank $\mathrm{CH}_{4}$, probably derived from the traps, was quantified by the same procedure as above (without sample introduction) and was lower than $0.3 \mu \mathrm{g}-\mathrm{C} \mathrm{CO}_{2}$.

Radiocarbon contents of $\mathrm{CO}_{2}$ in the ampules resulting from the above procedures were analyzed using MICADAS (the mini radiocarbon dating system), a gas ion source AMS, at the ETH-PSI laboratory in Zürich (Ruff et al., 2010; Wacker et al., 2016). The $\mathrm{CO}_{2}$ in the 6 mm-OD ampule prepared at JAMSTEC was transferred to $4 \mathrm{~mm}-\mathrm{OD}$ ampule at ETH for adaption for MICADAS manipulation. Device specification, analytical procedure, and data acquisition for the MICADAS ${ }^{14} \mathrm{C}$ analyses followed in the present study have been reported in detail in previous publications (Ruff et al., 2010; Wacker et al., 2016). Laboratory standards of ${ }^{14} \mathrm{C}$-known modern oxalic acid $\mathrm{OxII}$ and ${ }^{14} \mathrm{C}$-dead ancient $\mathrm{CO}_{2}$ were analyzed along with the samples. In this study, the radiocarbon content is presented in $\mathrm{F}^{14} \mathrm{C}$ (fraction of modern carbon) (Reimer et al., 2004) and pMC (percent modern carbon) that are defined as follows:

$$
\begin{gathered}
\mathrm{F}^{14} \mathrm{C}=\mathrm{A}_{\mathrm{SN}} / \mathrm{A}_{\mathrm{ON}}, \\
\mathrm{pMC}=\mathrm{F}^{14} \mathrm{C} \times 100,
\end{gathered}
$$

where $\mathrm{A}_{\mathrm{SN}}$ and $\mathrm{A}_{\mathrm{ON}}$ represent the $\delta^{13} \mathrm{C}$-normalized specific activities of the sample and OxII, respectively. Details of definition and calculation of $\mathrm{F}^{14} \mathrm{C}$ from the AMS measurement have been reported in previous publication (Reimer et al., 2004). Standard deviation of each $\mathrm{F}^{14} \mathrm{C}$ determination during individual sample analysis at AMS are presented along with the $\mathrm{F}^{14} \mathrm{C}$ values (Table 1).

\section{Results}

All ${ }^{14} \mathrm{C}$ data acquired in our study are shown in Table 1. Figure $2 \mathrm{a}$ shows results along with chronological order of the AMS analyses. The ${ }^{14} \mathrm{C}$ contents, without the modern OxII (Fig. 2b), were all lower than 4 pMC. If only considering the analytical uncertainties during the AMS analyses (Table 1), 5 of the 12 hydrothermal samples contained significant ${ }^{14} \mathrm{C}$, while the other 7 were completely ${ }^{14} \mathrm{C}$-dead (Fig. 2b). In order to interpret if the significant ${ }^{14} \mathrm{C}$ seen in these 5 hydrothermal samples truly represents ${ }^{14} \mathrm{C}$ contained in the seafloor hydrothermal fluids or is due to contamination, we must take into consideration and critically appraise the possible sources of ${ }^{14} \mathrm{C}$ contamination, as discussed below.

The ${ }^{14} \mathrm{C}$ contents of the ancient $\mathrm{CO}_{2}$ gas standards, measured in the same way as the modern standards, were significantly positive at $0.62 \pm 0.10$ and $0.75 \pm 0.15 \mathrm{pMC}$ (Table 1). This ${ }^{14} \mathrm{C}$ level would correspond to the ${ }^{14} \mathrm{C}$ blank during sample manipulation at the ETH-AMS laboratory, although memory effect from the OxII processing may 

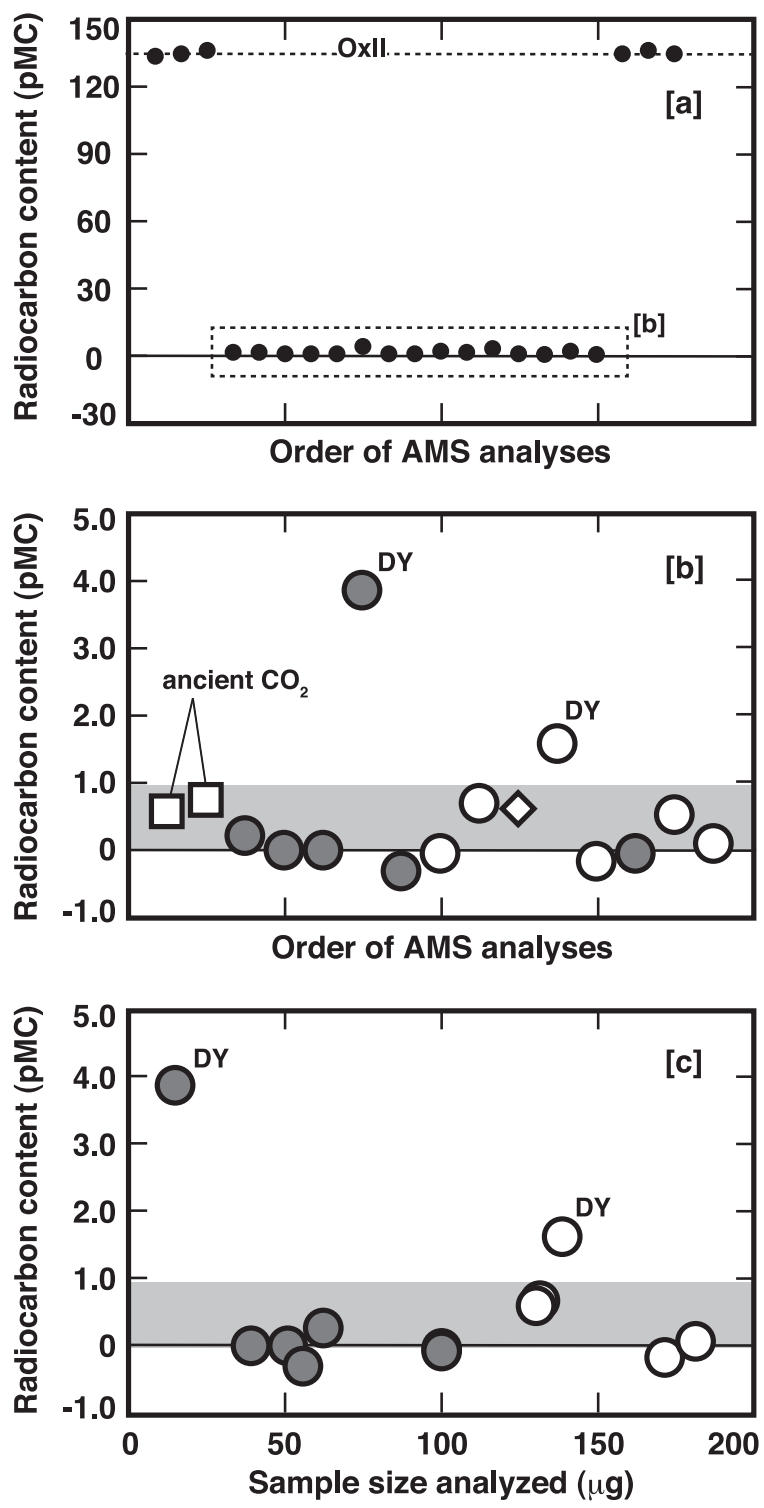

Fig. 2. All y axes represent ${ }^{14} C$ content in $p M C$. (a) All the results of AMS analysis including modern carbon standards $O x I I$ are shown in chronological order. (b) Open and filled circles represent hydrothermal samples of $\mathrm{CO}_{2}$ and $\mathrm{CH}_{4}$, respectively. Circles marked by DY are samples from Daiyon-Yonaguni site. Open squares and diamond represent ancient $\mathrm{CO}_{2}$ provided directly to the ETH-AMS and processed at JAMSTEC laboratory, respectively. Symbol size is comparable to analytical errors at AMS. Shade represents a blank level at AMS analysis. (c) Samples arranged by sample size introduced to ETH-AMS system.

have resulted in such (slightly high) blank levels. The ${ }^{14} \mathrm{C}$ dead-certified commercial $\mathrm{CO}_{2}$ processed in JAMSTEC showed $0.63 \pm 0.14 \mathrm{pMC}$, comparable to the ancient $\mathrm{CO}_{2}$ provided at the ETH-AMS laboratory. When the ${ }^{14} \mathrm{C}$ blank as high as 0.9 pMC from MICADAS manipulation is ap- plied, the ${ }^{14} \mathrm{C}$ contents in 2 samples collected at the DY site still remain significantly positive (Fig. 2 b).

The highest ${ }^{14} \mathrm{C}$ value of $3.88 \pm 0.28$ pMC was acquired from the $\mathrm{DY} \mathrm{CH}_{4}$-derived $\mathrm{CO}_{2}$ sample containing $13 \mu \mathrm{g}-\mathrm{C}$ (Fig. 2c), the smallest sample size in this study, while the MICADAS used herein was certified to be able to reliably measure $\mathrm{CO}_{2}$ samples containing carbon as small as $8 \mu \mathrm{g}$ (Ruff et al., 2010). The other significantly positive ${ }^{14} \mathrm{C}$ content of $1.62 \pm 0.18 \mathrm{pMC}$ was acquired from the $\mathrm{DY} \mathrm{CO}_{2}$ sample while all hydrothermal $\mathrm{CO}_{2}$ samples were processed with $>\sim 100 \mu \mathrm{g}-\mathrm{C}$. The Yokosuka $\mathrm{CO}_{2}$ contained ${ }^{14} \mathrm{C}$ as high as the AMS blank level, while $\mathrm{CO}_{2}$ from the other three sites were determined to be completely ${ }^{14} \mathrm{C}$-dead.

Seawater entrained at the time of seafloor sampling is another contaminant where modern $\mathrm{CO}_{2}$ could be introduced into the fluid samples, as deep-sea water in the Okinawa Trough contains modern DIC ( $2.3 \mathrm{mM}$ with 85 pMC) (Honda et al., 2000). Since magnesium is enriched in seawater $(53 \mathrm{mM}-\mathrm{Mg}$ ) but depleted in the endmember hydrothermal fluid $(0 \mathrm{mM}-\mathrm{Mg})$, magnesium concentrations in the fluid samples can be used as a proxy of the contribution ratio of seawater ( $\mathrm{SW}), f$, to the discharging hydrothermal fluid (HF) in the samples collected:

$$
\begin{aligned}
& {[\mathrm{Mg}]_{\text {sample }}=(1-f) \times[\mathrm{Mg}]_{\mathrm{HF}}+f \times[\mathrm{Mg}]_{\mathrm{SW}}} \\
& f=[\mathrm{Mg}]_{\text {sample }} / 53 .
\end{aligned}
$$

Using $f$, the isotope mass balance calculation for the subtraction of seawater-derived ${ }^{14} \mathrm{C}$ signature can provide $\mathrm{F}^{14} \mathrm{C}_{\mathrm{CO} 2}$ of the fluid as followings:

$$
\begin{aligned}
& {\left[\mathrm{CO}_{2}\right]_{\text {sample }}=(1-f) \times\left[\mathrm{CO}_{2}\right]_{\mathrm{HF}}+f \times\left[\mathrm{CO}_{2}\right]_{\mathrm{SW}}} \\
& \mathrm{F}^{14} \mathrm{C}_{\text {sample }} \times\left[\mathrm{CO}_{2}\right]_{\text {sample }} \\
& =(1-f) \times \mathrm{F}^{14} \mathrm{C}_{\mathrm{HF}} \times\left[\mathrm{CO}_{2}\right]_{\mathrm{HF}}+f \times \mathrm{F}^{14} \mathrm{C}_{\mathrm{SW}} \times\left[\mathrm{CO}_{2}\right]_{\mathrm{SW}} \cdot(6)
\end{aligned}
$$

For example, applying this calculation for the DY sample generates the endmember fluid $\mathrm{CO}_{2}$ concentration and ${ }^{14} \mathrm{C}$ content of $106 \mathrm{mM}$ and $1.55 \mathrm{pMC}$, respectively (Table 1). As only negligible $\mathrm{CH}_{4}(<1 \mathrm{nM})$ occurs in deepsea water in the western Pacific (e.g., Kawagucci et al., 2018a), its contribution should be negligible (not calculated).

Furthermore, contamination of air during sample processing may have serious impacts, because $\mathrm{CO}_{2}$ and $\mathrm{CH}_{4}$ make up $\sim 400 \mathrm{ppmv}$ and $\sim 2$ ppmv of air and exhibit ${ }^{14} \mathrm{C}$ content of 110 and $130 \mathrm{pMC}$, respectively (Hua et al., 2013; Wahlen et al., 1989). Sensitivity of the $\mathrm{F}^{14} \mathrm{C}$ values of the subsample (that was analyzed with AMS) against air contamination into the sample can also be calculated using isotope mass balance, as follows: 

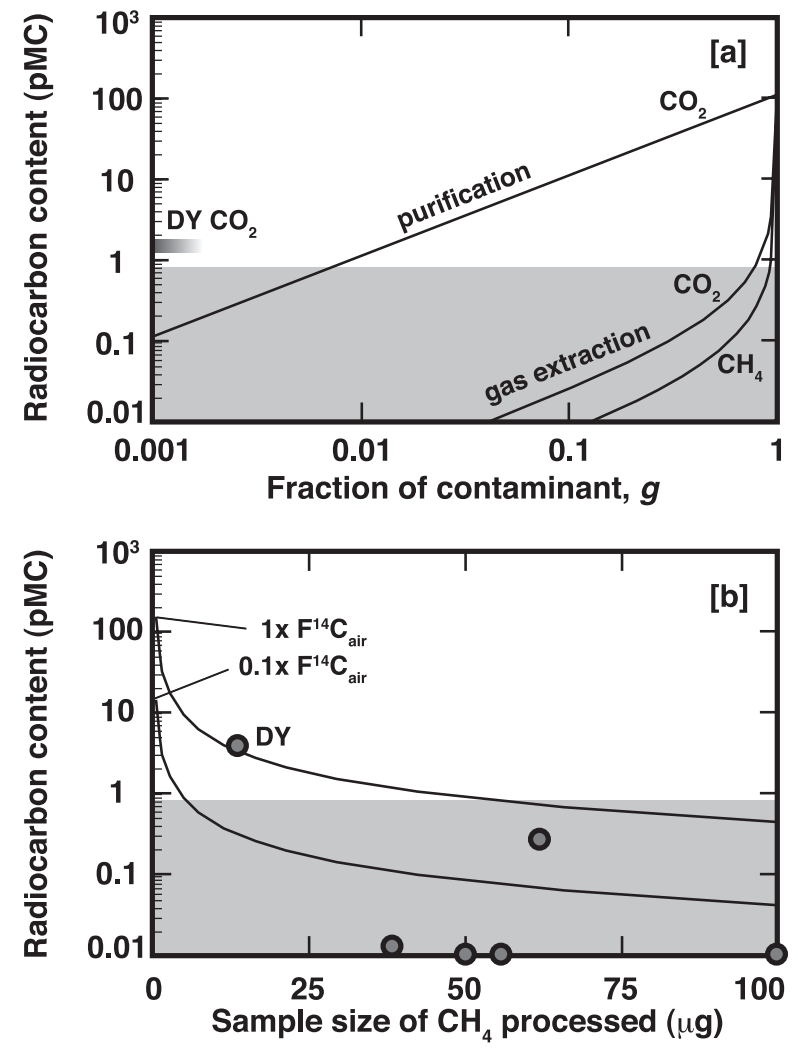

Fig. 3. Possible variation of radiocarbon content associated with air contamination. (a) Possible radiocarbon contents as a function of relative contribution of contaminant for the sample gas (assuming $\mathrm{O} \mathrm{pMC}$ in both $\mathrm{CO}_{2}$ and $\mathrm{CH}_{4}$ ) at onboard gas extraction (curves) and shore-based $\mathrm{CO}_{2}$ purification (line). For $\mathrm{DY} \mathrm{CO}_{2}, \mathrm{~g}$ is expected at $<0.001$. (b) Possible radiocarbon contents of $\mathrm{CH}_{4}$ as a function of sample size processed at the purification and oxidation line. Curves represent mixings between the $0.3 \mu \mathrm{g}-\mathrm{C}$ blank with radiocarbon contents of $130 \mathrm{pMC}$ $\left(=F^{14} C_{a i r}\right)$ or $13 \mathrm{pMC}\left(=0.1 \times F^{14} C_{a i r}\right)$ and ideal $\mathrm{CH}_{4}$ sample having $0 \mathrm{pMC}$.

$[\mathrm{C}]_{\text {subsample }}=(1-g) \times[\mathrm{C}]_{\text {sample }}+g \times[\mathrm{C}]_{\text {air }}$

$\mathrm{F}^{14} \mathrm{C}_{\text {subsample }} \times[\mathrm{C}]_{\text {subsample }}$

$=(1-g) \times \mathrm{F}^{14} \mathrm{C}_{\text {sample }} \times[\mathrm{C}]_{\text {sample }}+g \times \mathrm{F}^{14} \mathrm{C}_{\mathrm{air}} \times[\mathrm{C}]_{\mathrm{air}}$,

where $[\mathrm{C}]$ and $g$ represent $\left[\mathrm{CO}_{2}\right]$ or $\left[\mathrm{CH}_{4}\right]$ (in ppmv) and the relative contribution of air, respectively. Assuming $\mathrm{F}^{14} \mathrm{C}_{\text {sample }}$ is zero, Eq. (8) can be rewritten as:

$$
\mathrm{F}^{14} \mathrm{C}_{\text {subsample }}=\left\{g \times \mathrm{F}^{14} \mathrm{C}_{\text {air }} \times[\mathrm{C}]_{\text {air }}\right\} /[\mathrm{C}]_{\text {subsample }} .
$$

The barometrical monitoring during the ship-board processing $(<0.1 \mathrm{kPa}$-blank for $>17 \mathrm{kPa}$-subsample, see Subsection "Purification and oxidation") demonstrated that the actual value of $\mathrm{g}$ was $<0.01$. It is known that local $\left[\mathrm{CO}_{2}\right]_{\text {air }},\left[\mathrm{CH}_{4}\right]_{\text {air }}, \mathrm{F}^{14} \mathrm{C}_{\mathrm{CO} 2 \text { _air }}$, and $\mathrm{F}^{14} \mathrm{C}_{\mathrm{CH} 4 \text { _air }}$ were no

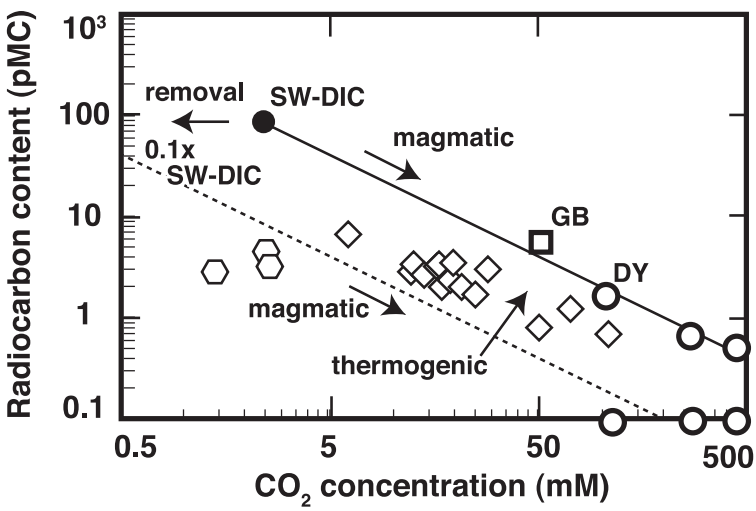

Fig. 4. Radiocarbon contents and concentrations of hydrothermal fluid $\mathrm{CO}_{2}$. Open symbols represent radiocarbon contents of hydrothermal fluid $\mathrm{CO}_{2}$ from Guaymas Basin (square) (Pearson et al., 2005), Endeavour (diamond) (Proskurowski et al., 2004), Von Damm (hexiagon) (McDermott et al., 2015), and Daiyon-Yonaguni (circle, this study). Filled circle represents seawater dissolved inorganic carbon (SW-DIC). Line and broken line respectively represent mixings of $S W$-DIC or a tenth of it with ${ }^{14} \mathrm{C}$-dead magmatic $\mathrm{CO}_{2}$. Contribution of thermogenic $\mathrm{CO}_{2}$ originating from ${ }^{14} \mathrm{C}$-containing sediment can increase both concentration and ${ }^{14} \mathrm{C}$ content of $\mathrm{CO}_{2}$.

higher than $1000,5,1.1$, and 1.3, respectively. Given that $\left[\mathrm{CO}_{2}\right]_{\text {subsample }}$ and $\left[\mathrm{CH}_{4}\right]_{\text {subsample }}$ were not lower than 500,000 and 10,000 (see Subsection "Purification and oxidation"), respectively, the calculated $\mathrm{F}^{14} \mathrm{C}_{\text {subsample val- }}$ ues were lower than 0.001 (0.1 pMC) for both $\mathrm{CO}_{2}$ and $\mathrm{CH}_{4}$ even for $g$ as large as 0.1 (Fig. 3a).

To evaluate the blank effect at the shore-based purification stage based on barometrical monitoring of accumulated $\mathrm{CO}_{2}$, where every $(\mathrm{C})$ were the same due to purification $\left(100 \% \mathrm{CO}_{2}\right)$, Eq. (9) was simplified to the following:

$$
\mathrm{F}^{14} \mathrm{C}_{\text {sample }}=x \times \mathrm{F}^{14} \mathrm{C}_{\text {contaminant }}
$$

where $x$ represents the relative contribution of the line blank $\mathrm{CO}_{2}$ to the $\mathrm{CO}_{2}$ in the ampule. The quantity of $\mathrm{CO}_{2}$ sealed into the glass ampule was estimated based on the barometrical monitoring during processing $(<0.1 \mu \mathrm{g}-\mathrm{C}$ blank for $\sim 100 \mu \mathrm{g}$-C-sample in the vacuum line, see Subsection "Purification and oxidation"), demonstrating that $x<0.001$. Even when assuming $\mathrm{F}^{14} \mathrm{C}_{\text {contaminant }}$ as high as $\mathrm{F}^{14} \mathrm{C}_{\text {air_CO2 }}$ of 1.1 (110 pMC), the calculated $\mathrm{F}^{14} \mathrm{C}_{\text {subsample_CO2 }}$ value was lower than 0.0013 (0.13 pMC) (Fig. 3a). As such, contamination alone cannot explain the significantly positive $\mathrm{F}^{14} \mathrm{C}_{\mathrm{CO} 2}$ value detected from the DY sample (Fig. 3a).

For $\mathrm{CH}_{4}$, the blank level was as high as $0.3 \mu \mathrm{g}-\mathrm{C}$. On one hand, analysis of $13 \mu \mathrm{g}-\mathrm{C}$ of ${ }^{14} \mathrm{C}$-dead $\mathrm{CH}_{4}$ can 
achieve ${ }^{14} \mathrm{C}$ content of $3.4 \mathrm{pMC}$ when applying $\mathrm{F}^{14} \mathrm{C}_{\text {air }} \mathrm{CH} 4$ of 1.3 for $\mathrm{F}^{14} \mathrm{C}_{\text {conatminant_CH4 }}$ (Fig. 3b). This calculated ${ }^{14} \mathrm{C}$ content of 3.4 pMC seemed comparable to 3.88 pMC acquired from the DY $\mathrm{CH}_{4}$ sample analysis. On the other hand, although the $\mathrm{F}^{14} \mathrm{C}$ value of the blank gas cannot be quantified due to its small quantity, it would be an order of magnitude lower than 1.3, as demonstrated by four other samples with $\mathrm{F}^{14} \mathrm{C}_{\mathrm{CH} 4}$ values of $<0.001$ (Fig. $3 b$ ). Indeed, the purification line has so far only been used for geological and geofluid-derived samples, which would contain little ${ }^{14} \mathrm{CH}_{4}$ and ${ }^{14} \mathrm{CO}_{2}$. Nevertheless, the above calculation suggests that contamination alone may explain the significantly positive ${ }^{14} \mathrm{C}$ content of $\mathrm{CH}_{4}$ from the DY sample.

\section{Discussion}

The critical evaluation of sample quality and contamination potentials indicated that the hydrothermal gas collected at the DY site undoubtedly contained a significant amount of ${ }^{14} \mathrm{C}$ in $\mathrm{CO}_{2}$, and possibly in $\mathrm{CH}_{4}$. Subseafloor hydrothermal fluid circulation includes four carbon reservoirs: seawater, magma, host rocks, and sediment (McCollom, 2008). Of these, carbon in magma and host rocks must be ${ }^{14} \mathrm{C}$ dead, as these carbon sources have a geological-scale age. In addition to seawater DIC (2.3 $\mathrm{mM}, 85 \mathrm{pMC}$ ), sediments younger than $20 \mathrm{ky}$ old within $\sim 20 \mathrm{~m}$ below the seafloor of the Okinawa Trough likely contains significant ${ }^{14} \mathrm{C}$ in the form of organic matter. Thermal degradation of this ${ }^{14} \mathrm{C}$-containing, sedimentary organic matter by interaction with ascending fluids results in the simultaneous production of $\mathrm{CO}_{2}$ and $\mathrm{CH}_{4}$ that contains ${ }^{14} \mathrm{C}$ (e.g., Kawagucci and Seewald, 2019). Dissolved organic matter in the deep-sea water also contains some ${ }^{14} \mathrm{C}(\sim 40 \mu \mathrm{M}, 50 \mathrm{pMC})$ (Williams and Druffel, $1987)$, but is negligible in quantity.

Seawater DIC recharged at the initial stage of hydrothermal circulation may serve as a source of ${ }^{14} \mathrm{CO}_{2}$ in the venting fluid $\mathrm{CO}_{2}$ (Fig. 4), although quantitative conservation of the recharged DIC has been much debated (Proskurowski et al., 2004). A simple calculation for magmatic ${ }^{14} \mathrm{C}$-dead $\mathrm{CO}_{2}$ addition to seawater DIC can indeed yield values that characterize the DY $\mathrm{CO}_{2}(106$ $\mathrm{mM}, 1.55 \mathrm{pMC}$ ) (Fig. 4). The quantitative conservation of SW-DIC is, however, not supported by other fluids with ${ }^{14} \mathrm{C}$-dead $\mathrm{CO}_{2}$ reported herein or from a previous study (Proskurowski et al., 2004) (Fig. 4). The possible removal of DIC during subseafloor fluid circulation is implied, for example, from calcium carbonate veins in altered oceanic crust (Alt and Teagle, 1999), whereas active hightemperature hydrothermal system differs from the off-axis oceanic crust with respect to residence time, temperature, and host rock acidity.

Two possible explanations are feasible to account for the presence/absence of ${ }^{14} \mathrm{C}$ in the Okinawa Trough vent fluids: i) the degrees and persistence of recharged SWDIC during subseafloor fluid-rock interaction are variable among different hydrothermal sites and happens to be high at the DY site, and ii) recharged seawater DIC is completely removed at every site while the thermogenic ${ }^{14} \mathrm{CO}_{2}$ input via subseafloor fluid-sediment interaction is significant at some sites, including DY. The apparently ${ }^{14} \mathrm{C}$-dead $\mathrm{CO}_{2}$ in other Okinawa Trough vent sites (Hatoma, Hitoshi, Noho) indicate that the recharged DIC has been completely removed and only negligible sedimentary carbon has been provided in these sites. The ${ }^{14} \mathrm{CO}_{2}$ in the DY fluid can reflect either the recharged DIC or sedimentary carbon, or a combination of both.

Thermal degradation of sedimentary ${ }^{14} \mathrm{C}$-containing carbon may contribute to ${ }^{14} \mathrm{CO}_{2}$ and ${ }^{14} \mathrm{CH}_{4}$ in the fluid of DY site. An example of thermogenic ${ }^{14} \mathrm{CO}_{2}$ and ${ }^{14} \mathrm{CH}_{4}$ input has been reported from the Guaymas Basin site in the Gulf of California, where the upwelling fluid passes through a $>1 \mathrm{~km}$-thick sediment layer (Pearson et al., 2005) resulting in abundant ${ }^{14} \mathrm{CO}_{2}(50 \mathrm{mM}, 5.6 \mathrm{pMC})$ (Fig. 4) as well as ${ }^{14} \mathrm{CH}_{4}$ (53 mM, $7.5 \mathrm{pMC}$ ) in the venting fluids (Pearson et al., 2005; Proskurowski et al., 2008). Topographical characteristics of the DY site, a valley where high sedimentation rate is expected due to particles coming from the surrounding walls, enables an environmental setting suitable for relatively young sediment interaction with upwelling fluid beneath the hydrothermal vent. On the other hand, vents of the other four Okinawa Trough sites studied here are located at the top or on the slope of knolls (Nakamura et al., 2015; Toki et al., 2016; Miyazaki et al., 2017b). Presumably, negligible fluid-sediment interaction within the upwelling zone in this environmental setting (Ishibashi et al., 2014b) results in negligible ${ }^{14} \mathrm{CO}_{2}$ and ${ }^{14} \mathrm{CH}_{4}$ as observed for fluids from these sites.

Large variations of ${ }^{13} \mathrm{C}$ content of $\mathrm{CO}_{2}$ and $\mathrm{CH}_{4}$ (Table 1) are known among the Okinawa Trough sites (Kawagucci et al., 2013), however, their sources remain consistent with the almost ubiquitously ${ }^{14} \mathrm{C}$-dead signatures reported here. For $\mathrm{CO}_{2}$, magmatic gas is considered to be the predominant source for $\mathrm{CO}_{2}$ in vent fluids at hydrothermal sites located at convergent plate boundaries (e.g., Lupton et al., 2008). The ${ }^{13} \mathrm{C}$ content of magmatic $\mathrm{CO}_{2}$ is controlled by the mixing ratio between ${ }^{13} \mathrm{C}$ rich subducting carbonate and ${ }^{13} \mathrm{C}$-depleted subducting organic matter (Sano and Marty, 1995), while both types of subducting carbon have spent geological time sufficient to extinguish ${ }^{14} \mathrm{C}$. Conversely, for $\mathrm{CH}_{4}$, the ${ }^{13} \mathrm{C}$ variation among the Okinawa Trough vent sites has been explained by differences in processes, instead of the carbon source. When based on deeply-buried sedimentary organic carbon which is dominated by ${ }^{13} \mathrm{C}$-rich ${ }^{14} \mathrm{C}$-dead carbon, variations in ${ }^{13} \mathrm{C}$ content with consistently ${ }^{14} \mathrm{C}$-dead sig- 
natures can result from larger/smaller kinetic isotope effects on the two processes of methanogenesis, namely microbial metabolism (Valentine et al., 2004; Okumura et al., 2016) and thermal decomposition (Seewald et al., 1994; Kawagucci and Seewald, 2019).

\section{SUMmary AND CONCLUDING REMARKS}

Our analyses of $\mathrm{CO}_{2}$ and $\mathrm{CH}_{4}$ radiocarbon contents in hydrothermal fluids collected at 5 vent sites in the Okinawa Trough provide preliminary insights on how different carbon sources and circulation processes contribute to vent fluids. The ${ }^{14} \mathrm{C}$-dead $\mathrm{CO}_{2}$ values observed in fluids at three Okinawa Trough sites (Hatoma, Hitoshi, Noho) demonstrate that the recharged DIC had been completely removed during subseafloor hydrothermal circulation, while the persistence of seawater DIC until the venting has been discussed. Factors controlling the persistence of the recharged DIC, such as residence time, temperature, and host rock type, remain unidentified. The significantly positive ${ }^{14} \mathrm{CO}_{2}$, and possibly ${ }^{14} \mathrm{CH}_{4}$, of the fluids detected in the DY site implies a contribution from thermal degradation of sedimentary ${ }^{14} \mathrm{C}$-containing carbon during fluid upwelling, and is consistent with its topographic setting at the bottom of a valley. The abundant $\mathrm{CH}_{4}$ in Okinawa Trough vent fluids were ${ }^{14} \mathrm{C}$-dead or nearly ${ }^{14} \mathrm{C}$-dead, which suggests a predominant source from deeply-buried ${ }^{14} \mathrm{C}$-dead sedimentary carbon.

These results serve as evidence that the procedures described herein, which combine deep-sea geofluid sampling, gas extraction onboard, purification at laboratory in JAMSTEC, and AMS analyses based in ETH, can quantify ${ }^{14} \mathrm{CO}_{2}$ content in $\mathrm{CO}_{2}$-rich geofluids as low as 0.9 pMC (Fig. 3a). The accumulation of blank $\mathrm{CO}_{2}$ throughout the procedure of $\mathrm{F}^{14} \mathrm{C}_{\mathrm{CH} 4}$ analysis was as low as 0.3 $\mu \mathrm{g}-\mathrm{C}$, while $\mathrm{F}^{14} \mathrm{C}$ values of the blank could not be determined. In this situation, the accurate quantification limit of $\mathrm{F}^{14} \mathrm{C}$, three times higher than the blank level, is as low as $1.5 \mathrm{pMC}$ when processing $>100 \mu \mathrm{g}-\mathrm{C}$ of $\mathrm{CH}_{4}$ (Fig. 3b). Sampling using the WHATS-series samplers (50 or 150 $\mathrm{mL}$ ) for $>0.1 \mathrm{mM}$ concentrations of carbon compounds in seafloor geofluids bring $>\sim 60 \mu \mathrm{g}-\mathrm{C}$ on-board the research vessel. This appears to be sufficient for carrying out the ${ }^{14} \mathrm{C}$ analyses using our procedure, although not quite ideal when the blank levels during $\mathrm{CH}_{4}$ processing is considered. This will be the target of methodological improvements, especially to reduce blank levels at the JAMSTEC laboratory. Nevertheless, we consider the procedures reported here to be a useful approach for studying radiocarbon contents in geofluids. Future research applying this method or an improved version of it to elucidate radiocarbon contents of deep-sea hydrothermal fluids in settings lacking sediments will be a valuable window to understand carbon circulation beneath the seafloor.
Acknowledgments-We thank Negar Haghipour and Daniel Montluçon for assisting with AMS analyses and sample preparation at ETH. We are greatly indebted to Keiko Tanaka who always set up excellent laboratory environments for us in JAMSTEC, and Chong Chen who significantly improved the English language of this paper. Parts of this study were supported by the Ministry of Education, Culture, Sports, Science and Technology (MEXT) of the Government of Japan as grantin-aids (KAKEN-HI) Nos. 17H01869 (to SK) and 16K00534 (to SK and YM).

\section{REFERENCES}

Alt, J. C. and Teagle, D. A. H. (1999) The uptake of carbon during altteration of ocean crust. Geochim. Cosmochim. Acta 63, 1527-1535.

Blattmann, T. M., Wang, S. L., Lupker, M., Märki, L. M. X., Haghipour, N., Wacker, L., Chung, L. H., Bernasconi, S. M., Plötze, M. P. X. and Eglinton, T. I. (2019) Sulphuric acid-mediated weathering on Taiwan buffers geological atmospheric carbon sinks. Nature Publishing Group, 1-8.

Elderfield, H. and Schultz, A. (1996) Mid-Ocean Ridge hydrothermal fluxes and the chemical composition of the ocean. Annu. Rev. Earth Planet. Sci., 191-224.

Haghipour, N., Ausin, B., Usman, M. O., Ishikawa, N., Wacker, L., Welte, C., Ueda, K. and Eglinton, T. I. (2019) Compoundspecific radiocarbon analysis by elemental analyzer-Accelerator mass spectrometry: Precision and limitations. Anal. Chem. 91, 2042-2049.

Honda, M. C., Kusakabe, M., Nakabayashi, S. and Katagiri, M. (2000) Radiocarbon of sediment trap samples from the Okinawa trough: lateral transport of ${ }^{14} \mathrm{C}$-poor sediment from the continental slope. Mar. Chem. 68, 231-247.

Hua, Q., Barbetti, M. and Rakowski, A. Z. (2013) Atmospheric radiocarbon for the period 1950-2010. Radiocarbon 55, 2059-2072.

Ijiri, A., Wang, L., Oba, T., Kawahata, H., Huang, C.-Y. and Huang, C.-Y. (2005) Paleoenvironmental changes in the northern area of the East China Sea during the past 42,000 years. Palaeogeogr., Palaeoclimatol., Palaeoecol. 219, 239261.

Ishibashi, J.-I., Ikegami, F., Tsuji, T. and Urabe, T. (2014a) Hydrothermal activity in the Okinawa Trough Back-Arc Basin: Geological background and hydrothermal mineralization. Subseafloor Biosphere Linked to Hydrothermal Systems Springer Japan, 337-359, Tokyo.

Ishibashi, J.-I., Noguchi, T., Toki, T., Miyabe, S., Yamagami, S., Onishi, Y., Yamanaka, T., Yokoyama, Y., Omori, E., Takahashi, Y., Hatada, K., Nakaguchi, Y., Yoshizaki, M., Konno, U., Shibuya, T., Takai, K., Inagaki, F. and Kawagucci, S. (2014b) Diversity of fluid geochemistry affected by processes during fluid upwelling in active hydrothermal fields in the Izena Hole, the middle Okinawa Trough back-arc basin. Geochem. J. 48, 357-369.

Ishikawa, N. F., Hyodo, F. and Tayasu, I. (2013) Use of carbon-13 and carbon-14 natural abundances for stream food web studies. Ecol. Res. 28, 759-769.

Kao, S. J. (2005) Enhanced deepwater circulation and shift of sedimentary organic matter oxidation pathway in the 
Okinawa Trough since the Holocene. Geophys. Res. Lett. 32, 255-4.

Kawagucci, S. (2014) Fluid geochemistry of high-temperature. Subseafloor Biosphere Linked to Hydrothermal Systems Springer Japan, Tokyo, doi:10.1007/978-4-431-548652330 .

Kawagucci, S. and Seewald, J. S. (2019) Compositional and isotopic characteristics of hydrocarbons generated by a hydrothermal experiment simulating seafloor sediment alteration stepwise heating from 275 to $361^{\circ} \mathrm{C}$ at $30 \mathrm{MPa}$. Geochem. J. 53, 281-291.

Kawagucci, S., Ueno, Y., Takai, K., Toki, T., Ito, M., Inoue, K., Makabe, A., Yoshida, N., Muramatsu, Y., Takahata, N., Sano, Y., Narita, T., Teranishi, G., Obata, H., Nakagawa, S., Nunoura, T. and Gamo, T. (2013) Geochemical origin of hydrothermal fluid methane in sediment-associated fields and its relevance to the geographical distribution of whole hydrothermal circulation. Chem. Geol. 339, 213-225.

Kawagucci, S., Makabe, A., Kodama, T., Matsui, Y., Yoshikawa, C., Ono, E., Wakita, M., Nunoura, T., Uchida, H. and Yokokawa, T. (2018a) Hadal water biogeochemistry over the Izu-Ogasawara Trench observed with a full-depth CTDCMS. Ocean Sci. 14, 575-588.

Kawagucci, S., Miyazaki, J., Morono, Y., Seewald, J. S., Wheat, C. G. and Takai, K. (2018b) Cool, alkaline serpentinite formation fluid regime with scarce microbial habitability and possible abiotic synthesis beneath the South Chamorro Seamount. Prog. Earth Planet. Sci. 5, 74.

Konno, U., Tsunogai, U., Nakagawa, F., Nakaseama, M., Ishibashi, J.-I., Nunoura, T. and Nakamura, K.-I. (2006) Liquid $\mathrm{CO}_{2}$ venting on the seafloor: Yonaguni Knoll IV hydrothermal system, Okinawa Trough. Geophys. Res. Lett. 33, 725-5.

Lang, S. Q., Früh-Green, G. L., Bernasconi, S. M. and Wacker, L. (2013) Isotopic $\left(\delta^{13} \mathrm{C}, \Delta{ }^{14} \mathrm{C}\right)$ analysis of organic acids in marine samples using wet chemical oxidation. Limnol. Oceanogr. Methods 11, 161-175.

Lupton, J., Lilley, M., Butterfield, D., Evans, L., Embley, R., Massoth, G., Christenson, B., Nakamura, K.-I. and Schmidt, M. (2008) Venting of a separate $\mathrm{CO}_{2}$-rich gas phase from submarine arc volcanoes: Examples from the Mariana and Tonga-Kermadec arcs. J. Geophys. Res. 113, 354-21.

McCollom, T. M. (2008) Observational, experimental, and theoretical constraints on carbon cycling in mid-ocean ridge hydrothermal systems. Magma to Microbe Modeling Hydrothermal Processes at Oceanic Spreading Centers (Lowell, R., Seewald, J. S., Metaxas, A. and Perfit, M., eds.), 193-213, Wiley Online Library.

McDermott, J. M., Seewald, J. S., German, C. R. and Sylva, S. P. (2015) Pathways for abiotic organic synthesis at submarine hydrothermal fields. Proc. Natl. Acad. Sci. USA 112, 7668-7672.

Miyazaki, J., Makabe, A., Matsui, Y., Ebina, N., Tsutsumi, S., Ishibashi, J.-I., Chen, C., Kaneko, S., Takai, K. and Kawagucci, S. (2017a) WHATS-3: An Improved flowthrough multi-bottle fluid sampler for deep-sea geofluid research. Front. Earth Sci. 5, 202-213.

Miyazaki, J., Kawagucci, S., Makabe, A., Takahashi, A., Kitada, K., Torimoto, J., Matsui, Y., Tasumi, E., Shibuya, T.,
Nakamura, K., Horai, S., Sato, S., Ishibashi, J.-I., Kanzaki, H., Nakagawa, S., Hirai, M., Takaki, Y., Okino, K., Watanabe, H. K., Kumagai, H. and Chen, C. (2017b) Deepest and hottest hydrothermal activity in the Okinawa Trough: the Yokosuka site at Yaeyama Knoll. R. Soc. Open Sci. 4, 171570-20.

Nakamura, K., Kawagucci, S., Kitada, K., Kumagai, H., Takai, K. and Okino, K. (2015) Water column imaging with multibeam echo-sounding in the mid-Okinawa Trough: Implications for distribution of deep-sea hydrothermal vent sites and the cause of acoustic water column anomaly. Geochem. J. 49, 579-596.

Okumura, T., Kawagucci, S., Saito, Y., Matsui, Y., Takai, K. and Imachi, H. (2016) Hydrogen and carbon isotope systematics in hydrogenotrophic methanogenesis under $\mathrm{H}_{2}$-limited and $\mathrm{H}_{2}$-enriched conditions: implications for the origin of methane and its isotopic diagnosis. Prog. Earth Planet. Sci. 3, 219.

Pack, M. A., Xu, X., Lupascu, M., Kessler, J. D. and Czimczik, C. I. (2015) A rapid method for preparing low volume $\mathrm{CH}_{4}$ and $\mathrm{CO}_{2}$ gas samples for ${ }^{14} \mathrm{C}$ AMS analysis. Org. Geochem. 78, 89-98.

Pearson, A., Seewald, J. S. and Eglinton, T. I. (2005) Bacterial incorporation of relict carbon in the hydrothermal environment of Guaymas Basin. Geochim. Cosmochim. Acta 69, 5477-5486.

Proskurowski, G., Lilley, M. D. and Brown, T. A. (2004) Isotopic evidence of magmatism and seawater bicarbonate removal at the endeavour hydrothermal system. Earth Planet. Sci. Lett. 225, 53-61.

Proskurowski, G., Lilley, M. D., Seewald, J. S., Früh-Green, G. L., Olson, E. J., Lupton, J. E., Sylva, S. P. and Kelley, D. S. (2008) Abiogenic hydrocarbon production at lost city hydrothermal field. Science, 604-607.

Reimer, P. J., Brown, T. A. and Reimer, R. W. (2004) Discussion: reporting and calibration of post-bomb ${ }^{14} \mathrm{C}$ data. $R a$ diocarbon 46, 1299-1304.

Roberts, M. L., Schneider, R. J., von Reden, K. F., Wills, J. S. C., Han, B. X., Hayes, J. M., Rosenheim, B. E. and Jenkins, W. J. (2007) Progress on a gas-accepting ion source for continuous-flow accelerator mass spectrometry. Nuclear Instruments and Methods in Physics Research Section B: Beam Interactions with Materials and Atoms 259, 83-87.

Ruff, M., Szidat, S., Gäggeler, H. W., Suter, M., Synal, H.-A. and Wacker, L. (2010) Gaseous radiocarbon measurements of small samples. Nuclear Inst. and Methods in Physics Research, B 268, 790-794.

Saegusa, S., Tsunogai, U., Nakagawa, F. and Kaneko, S. (2006) Development of a multibottle gas-tight fluid sampler WHATS II for Japanese submersibles/ROVs. Geofluids $\mathbf{6}$, 234-240.

Sano, Y. and Marty, B. (1995) Origin of carbon in fumarolic gas from island arcs. Chem. Geol. 119, 265-274.

Seewald, J. S., Seyfried, W. E., Jr. and Shanks, W. C., III (1994) Variations in the chemical and stable isotope composition of carbon and sulfur species during organic-rich sediment alteration: An experimental and theoretical study of hydrothermal activity at guaymas basin, gulf of california. Geochim. Cosmochim. Acta 58, 5065-5082. 
Shao, H., Yang, S., Cai, F., Li, C., Liang, J., Li, Q., Hyun, S., Kao, S.-J., Dou, Y., Hu, B., Dong, G. and Wang, F. (2016) Sources and burial of organic carbon in the middle Okinawa Trough during late Quaternary paleoenvironmental change. Deep-Sea Res. Part I 118, 46-56.

Suzuki, R., Ishibashi, J.-I., Nakaseama, M., Konno, U., Tsunogai, U., Gena, K. and Chiba, H. (2008) Diverse range of mineralization induced by phase separation of hydrothermal fluid: Case study of the Yonaguni Knoll IV hydrothermal field in the Okinawa Trough Back-Arc Basin. Resour. Geol. 58, 267-288.

Synal, H.-A. (2013) Developments in accelerator mass spectrometry. Int. J. Mass Spectrom. 349-350, 192-202.

Toki, T., Itoh, M., Iwata, D., Ohshima, S., Shinjo, R., Ishibashi, J.-I., Tsunogai, U., Takahata, N., Sano, Y., Yamanaka, T., Ijiri, A., Okabe, N., Gamo, T., Muramatsu, Y., Ueno, Y., Kawagucci, S. and Takai, K. (2016) Geochemical characteristics of hydrothermal fluids at Hatoma Knoll in the southern Okinawa Trough. Geochem. J. 50, 493-525.

Trumbore, S. (2009) Radiocarbon and soil carbon dynamics. Annu. Rev. Earth Planet. Sci. 37, 47-66.

Valentine, D. L., Chidthaisong, A., Rice, A., Reeburgh, W. S. and Tyler, S. C. (2004) Carbon and hydrogen isotope fractionation by moderately thermophilic methanogens 1 associate editor: N. E. Ostrom. Geochim. Cosmochim. Acta 68, 1571-1590.

Wacker, L., Bonani, G., Friedrich, M., Hajdas I., Kromer, B., Némec, M., Ruff, M., Suter, M., Synal, H.-A. and Vockenhuber, C. (2016) MICADAS: Routine and high-precision radiocarbon dating. Radiocarbon 52, 252-262.

Wahlen, M., Tanaka, N., Henry, R., Deck, B., Zeglen, J., Vogel, J. S., Southon, J., Shemesh, A., Fairbanks, R. and Broecker, W. S. (1989) Carbon-14 in methane sources and in atmospheric methane: The contribution from fossil carbon. Science 245, 286-290.

Williams, P. M. and Druffel, E. R. M. (1987) Radiocarbon in dissolved organic matter in the central North Pacific Ocean. Nature 330, 246-248.

Wu, J.-N., Chiang, H.-T., Chiao, L.-Y., Shyu, C.-T., Liu, C.-S., Wang, Y. and Chen, S.-C. (2019) Revisiting the data reduction of seafloor heat-flow measurement: The example of mapping hydrothermal venting site around Yonaguni Knoll IV in the South Okinawa Trough. Tectonophysics, 228159. 